\title{
Factors Influencing Educational Adjustment among English Medium Students in Kottayam Diocese, Kerala, India: A Path Analytic Study
}

\author{
*Parvathy Varma, Marykutty, K. L. \\ Assumption University of Thailand, Bangkok, Thailand \\ *parvathyvarma@hotmail.com
}

\begin{abstract}
The purpose of this study was to investigate the direct and indirect influence of parental involvement on Educational Adjustment among English Medium Students in Kottayam Diocese, Kerala, India, being mediated by Self-efficacy, English language anxiety, and mathematics anxiety. This quantitative research employed path analysis to investigate the study's hypotheses. A total of 300 participants were selected via convenient sampling participated in the study. The path model showed that, the respondents' their perceived level of parental involvement has a direct influence on their reported level of educational adjustment. Thus, the more they perceived their parents' involvement in their academic life, the higher their reported level of educational adjustment. Parental involvement was also found to have an indirect influence on their educational adjustment, being mediated by their reported level of self-efficacy. Thus, the more the respondents perceived their parents' involvement in their academic life, the higher their level of self-efficacy; subsequently, the higher their level of selfefficacy, the higher their reported level of educational adjustment. Self-efficacy was also found to be positively related to English language anxiety and negatively related to math anxiety. Thus, the higher the respondents' reported level of self-efficacy, the higher their reported level of English language anxiety and the lower their reported level of math anxiety. Neither English language anxiety nor math anxiety was found to be significantly related to the respondents' reported level of educational adjustment.
\end{abstract}

Keywords: Parental Involvement, Self-efficacy, English language anxiety, Mathematics anxiety, Educational Adjustment

\section{Introduction}

School is the major socialization institution for any child; it is the child's first contact with the world outside the house. In the Indian context, for nearly 12 years a child spends an average of seven hours a day in school. School is one of the most important foundation pillars on which the child's personality develops. Children learn proficiencies in various abilities such as learning process and homework, social communication, handling emotion, and the management of day-to-day interactions at home and at school. India has endeavored to provide quality education through the portals of its educational providers. Higher education and technological advancement have created job opportunities for Indians across the globe and, eventually, all those who could afford it have moved out for better educational adjustment (accommodation and adaptation), looking for high achieving schools. High school experience can be problematic for many students. It is the most vulnerable period for students in terms of probability of academic failure, dropping out of school, and increased social and emotional difficulties (Mclnnis, 2001). Positive adjustment to high school is a critical factor in influencing students' academic success. Entrance to high school symbolizes a challenging transitional step in students' lives. Students need to deal with more responsibilities and challenges upon entering high school. For many, successful and eventual separation from parents and family and establishment of emotional independence can have a positive influence on educational adjustment.

Parental involvement plays a significant role during this age of acquisition of new language. There is a strong relation between parent involvement and students' positive academic outcomes (Miedel \& Reynolds, 2000). Parents who actively participate in their children's schooling help them learn skills, including language skills, to succeed in school. The importance of home and school relations for increasing student success in school has been recognized in the research literature. Educational selfefficacy is a reliable predictor of students' motivation and learning (Zimmerman, 2000). Self-efficacy is closely related to self-concept; however, self-efficacy is a better indicator of the level of students' belief in their abilities and, subsequently, of performance (Tremblay \& Gardner, 1995). Self-efficacy contributes 
positively to language learning motivation. Developing a sense of self-efficacy in language early on tends to benefit student performance (Cotterall, 1999). On the other hand, students with low self-efficacy tend to focus on how difficult school life might be and doubt if they are able to manage. Therefore, they tend to experience more stress (Zajacova, Lynch, \& Espenshade, 2005). Misra, Crist, and Burant (2003) found that language problem is one of the many stressors students, particularly those from foreign countries, face at school. Linguistic anxiety often limits students from acquiring a second language effectively (Horwitz, 1986). Gardner and Lambert (1959) rated "motivational" factor as one of the top two factors (the other being "linguistic aptitude") in second language learning. Moreover, students with high anxiety assess the situation as a threat and as unmanageable, which often leads to poor academic performance or failure (Cohen, Ben-Zur, \& Rosenfeld, 2008). Less anxious learners tend to be more enthusiastic, engaged, and focused. They are interested in what they are doing and they try hard to overcome challenges (Garris, Ahlers, \& Driskell, 2002).

A study by Dirkx (2001) found that emotions are significant in education because it can either obstruct or stimulate learning. Mathematics anxiety is such an emotion. It can motivate a learner to practice and solve many mathematical calculations and problems, or it can paralyze another in such a way that he or she cannot perform even rudimentary arithmetic in mathematics. Research in mathematics education suggests that mathematics anxiety, beliefs about mathematics, and mathematics self-efficacy are variables contributing to or hindering success in mathematics (Walsh, 2008). Burns (1998) found that two thirds of U.S. students "fear and loathe" math. Researchers have shown that even students with proven mathematics ability can experience mathematics anxiety that impairs their short-term memory and causes them to struggle in performing mathematical tasks (Ruffins, 2007). In private English medium schools where the medium of instruction is English, the academic and social lives of Indian students from non-English speaking backgrounds are influenced by their level of English language proficiency (Khawaja \& Dempsey, 2007). According to Dowdy, DiStefano, Dever, and Chin (2011), students with lower levels of English proficiency tend to have more school-related problems such as attention and learning difficulties. Students' limited language proficiency also limits their desire to seek social interactions and educational adjustment (Olivas \& Li, 2006); a finding that the current study attempts to confirm. Nonetheless, little do parents know that their children are neither prepared for, nor motivated to learn English as their second language, yet are thrust upon to learn its mastery?

Rationale for the Study: The current research on the educational adjustment is a relatively new phenomenon; therefore' fairly little research has been conducted in Kerala. The researcher believes that both teacher and parents play an important role in the overall development and effective functioning of educational adjustment in students. Investigating such new trend within the Indian context would give new insights into the realm of educational adjustment among local students. Today, most families in Kerala, India have succumbed to modernization and globalization as a consequent influence of Western culture. Parents realize that, in order for their children to secure lucrative job opportunities and career advancement, their children should learn to speak and write competently in English. It is no surprise that parents rush to private educational providers to seek admission for their children in the hope that by equipping them with a proficiency in English, their children's future career would be guaranteed. Lower levels of English language proficiency not only affect students' academic progress but also affect their experience of high school life in general. In private English Medium schools in India where the medium of instruction is English, the academic and social lives of students from non-English speaking backgrounds are influenced by their level of English language proficiency. In addition to language problems, other factors such as mathematics anxiety, lack of parental involvement, and low self-efficacy problems heighten the amount of stressors these students have to contend with. Considering this complex situation, the current researcher attempted to investigate the influence of certain identified factors on the educational adjustment of private English Medium high school students in the Kottayam District in Kerala, India with the intention that, in knowing the influence of these factors, workable intervention mechanisms aimed at facilitating the educational adjustment of the students can be recommended as a result of this empirical study.

Purpose of the Study: The general purpose of this study was to examine the factors influencing educational adjustment among English Medium students in Kottayam Diocese, Kerala, India. More specifically, this study aimed to: 
- Investigate the direct influence of parental involvement, self-efficacy, English language anxiety, and math anxiety on the educational adjustment of private English Medium high school students in Kottayam Diocese, Kerala, India.

- Investigate the indirect influence of parental involvement on educational adjustment, being mediated by self-efficacy, English language anxiety, and math anxiety.

- Examine gender difference in the students' parental involvement, self-efficacy, English language anxiety, math anxiety, and educational adjustment.

Scope of the Study: The current study would be a significant endeavor for a number of reasons. It would serve as a knowledge resource on the impact of parental involvement, English language anxiety, and mathematics anxiety as well as the mediating role of self-efficacy on educational adjustment among English Medium school students in India. The study would provide constructive information for schools to allow them to direct their resources and expertise toward developing and offering necessary support and counseling services intended to assist students in adjusting successfully to more advanced school work. This study's findings should help shed some light on effective academic interventions aimed at enhancing students' sense of hope, emotional competence, anxiety problem solving, as well as parentteacher-student intercommunication. Hence, the theoretical perspectives, results, and discussions of this study should be especially useful to teachers, school administrators and policy makers, social workers, family counselors, counseling psychologists, and parents in their desire to nurture students in the right direction and give substantial support to them during their high school years. Furthermore, for the benefit of other behavioral researchers, the results of this study would help to provide a conceptual framework to guide further empirical research in this area.

\section{Conceptual Framework}

Based on the preceding review of literature, the following conceptual framework was formulated. Figure 1 presents the path model of the predictive relationships among parental involvement, and educational adjustment, being mediated by self-efficacy, English_language anxiety, and math anxiety.

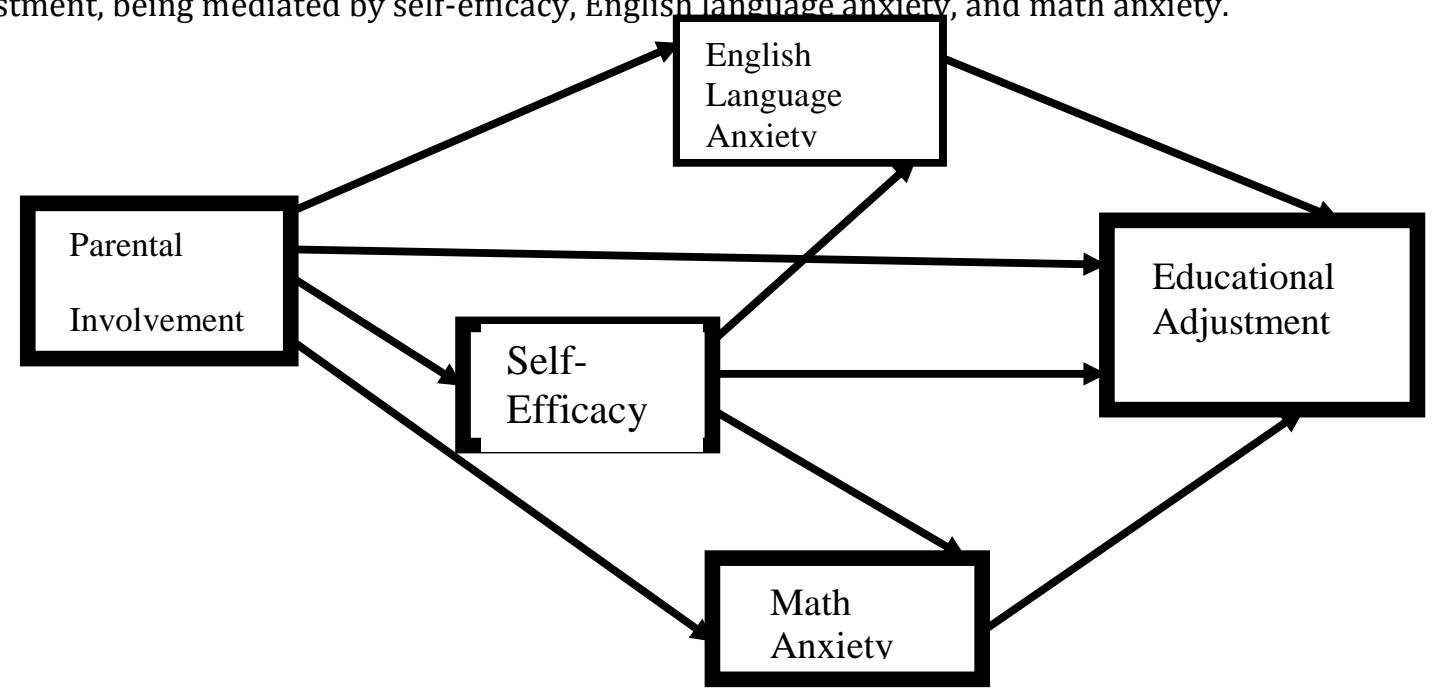

Figure 1: Path model of educational adjustment as a function of the direct and indirect influence of parental involvement on educational adjustment, being mediated by self-efficacy, English language anxiety, and math anxiety.

Research Hypotheses: Based on the review of literature, the conceptual framework, and the research questions, the following hypotheses were generated for purposes of testing in this study.

H1: Parental involvement has a direct influence on students' educational adjustment such that, the higher their level of parental involvement, the higher their level of educational adjustment.

H2: Self-efficacy has a direct influence on students' educational adjustment such that, the higher their level of their self-efficacy, the higher their level of educational adjustment. 
H3: English language anxiety and Math anxiety have a direct influence on students' educational adjustment such that, the higher their level of English language anxiety, and math anxiety, the lower their level of educational adjustment.

H4: Parental involvement has indirect influences on students' educational adjustment, being mediated by their self-efficacy such that, the lower their level of parental involvement, the lower their level of self-efficacy and, consequently, the lower their level of educational adjustment.

H5: Parental involvement has indirect influences on students' educational adjustment, being mediated by their self-efficacy, English language anxiety and math anxiety such that, the lower their level of parental involvement, the lower their level of self-efficacy and, consequently, the higher their level of English language anxiety and math anxiety and, subsequently, the lower their level of educational adjustment.

H6: There are significant gender differences in the students' parental involvement, self-efficacy, English language anxiety, math anxiety, and educational adjustment.

\section{Methodology}

Participants: The participants of this study consisted of students of private English medium schools under the Kottayam Diocese of Kerala, India. At the time of the study, there were approximately 2,29I students studying in seven private schools under the Kottayam Diocese. Kerala has $100 \%$ literacy and is the foremost state in India measured by Human Resources Development Index (HRDI) as per the planning commission. The researcher focused on students aged between 13 to 15 years old. The sample was selected by convenient sampling. Of the 300 participants, 137 (45.7\%) were males and 163 (54.3\%) were females.

Instruments: The proposed research instrument was a six-part, self-administered survey questionnaire. Part 1 was designed to elicit information about the participant's sex. Part II Parental Involvement Scale (PIS), which was found in the work of Hoover- Dempsey (2004). PIS are an 11-item measure of student's perceived parental involvement. The measure is a five point Likert scale that assessed the extent to which a student believes that their parents or caregivers are actively involved in their education. The three scale factors demonstrated adequate internal consistency with a Cronbach's alpha coefficient of .70. Part III General Self-Efficacy Scale (GSE) the English adaptation of the GSE scale was developed by Schwarzer and Jerusalem (1995). The scale was developed to measure a general sense of perceived self-efficacy in coping with daily hassles and adapting to stressful life events. The four point Likert scale is developed for the general adult population, including adolescents. Summing up the responses to all 10 items will yield the final composite score with a range from 10 to 40 . In samples from 23 nations, Cronbach's alphas ranged from .76 to .90 , with the majority in the high $.80 \mathrm{~s}$. The fourth part was the English Language Classroom Anxiety Scale (ELCAS). Horwitz et al. (1986) developed a questionnaire with 33 items to measure the level of anxiety experienced by foreign language students .The researcher adapted the questionnaire items in general and for the research made it as a 5 point Likert scale. The purpose of the scale is to examine the scope and perceptions of English language anxiety. The items 2, 5, 11, 14 and 22 are negative questions and are reverse-scored.

The fifth part is Mathematics Anxiety Rating Scale-Revised (MARS-R)( Barbara and Parker; 1982). The scale consists of 24 items which assess the level to which students experience anxiety related to involvement in statistics and mathematic courses. MARS-R was adapted by Barbara and Parker (1982) from Suinn's original Mathematics Anxiety Rating Scale which consisted of 98 items. The current version is more focused on situation- specific (state) anxiety general (trait) anxiety, and test anxiety. The instrument forms two subscales: learning math anxiety (LMA) which pertains to the process of learning math and statistics, and mathematic evaluation anxiety (MEA) which measures anxiety over being tested about math and statistics. Respondents rate each item on a 5-point scale ranging from: 1 = Low anxiety to $5=$ High anxiety. Scores are the sum of the ratings and range from 24 to 120 for the total scale. Part 6 is composed of the adapted form of the First Year Experience Questionnaire (FYEQ) [re-named Educational Adjustment Scale (EAS) for the purposes of this study] was used to measure aspects of participants' educational adjustment (Mclnnis \& James, 1995; Vernon-Livington, 2009). The FYEQ measures students' educational adjustment in high school. This questionnaire is grouped into three different dimensions of educational adjustment. For the purposes of this research, the researcher used only 34 items and avoided items which are not relevant for the targeted population. Scores on the 38 items may be combined to generate a whole-scale score for educational adjustment. Vernon-Livington (2009) reported that FYEQ 
has acceptable internal reliability with Cronbach's alpha $=0.50$ to 0.88 , while Dalziell and Peat (1998) suggested that the reliability of FYEQ was satisfactory with alpha $=0.40$ to 0.89 . In the current research, the following items (item numbers $6,8,28,29,30,31,32,33$, and 34) were reverse-scored so that a high score on the EAS (an adaptation of the FYEQ) indicated greater educational adjustment.

Data Collection Procedure and Data Analysis: The research employed convenience sampling method to obtain data from the targeted English medium students. The original questionnaire in English was translated into Malayalam by a bilingual expert and then back-translated to English by another bilingual expert to reduce bias and ensure translation consistency. Seven English Medium schools under Kottayam Diocese were selected for the data collection and with the teachers' cooperation; the questionnaires were distributed in the classes.

\section{Results}

In order to investigate gender differences for the five computed variables, GLM multivariate analysis of variance (MANOVA) was conducted. Results from the MANOVA showed that there was an overall gender effect for the five variables combined, $F(5,295)=8.16, p<.001$. Follow-up tests of between-subjects effects showed that gender has significant effect for all five dependent variables: parental involvement, $F(1,298)=5.43, p<.05$; self-efficacy, $F(1,298)=5.24, p<.05$; English language anxiety, $F(1,298)=10.47, p<.01$; math anxiety, $F(1,298)=13.51, p<.001$; and educational adjustment, $F(1,298)=12.34, p<.01$. Examination of the marginal means showed that (1) female respondents reported higher level of parental involvement $(M=4.35)$, higher level of self-efficacy $(M=3.20)$, higher math anxiety $(M=2.94)$, and better educational adjustment $(M=4.04)$ than their male counterparts $(M=4.23, M=3.09, M=2.63$, and $M=3.85$, respectively), and (2) male respondents reported higher level of English language anxiety $(M=3.44)$ than their female counterparts $(M=3.19)$.

Path Analysis: In order to test the hypothesized direct and indirect relationships represented by the path model presented in Figure 1, path analysis via regression analysis was conducted. The analysis involved (1) regressing the dependent variable of educational adjustment on the predictor variables of parental involvement, self-efficacy, English language anxiety, and math anxiety; (2) regressing English language anxiety and math anxiety on the predictor variables of parental involvement and self-efficacy; and (3) regressing self-efficacy on the predictor variable of parental involvement. The results of this path analysis are presented in Figure 2. In order to aid the interpretation of the results, only path coefficients that are statistically significant $(p<.05)$ have been included in the figure.

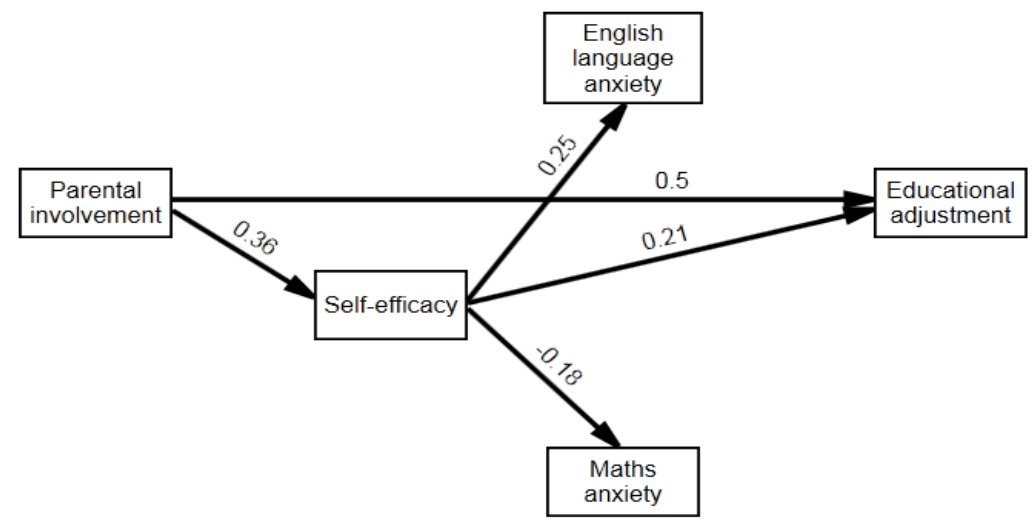

Figure 2: Results of path analysis of educational adjustment as a function of the direct and indirect influences (being mediated by the respondents' level of English language anxiety, math anxiety, and selfefficacy) of their perceived level of parental involvement.

The results showed that for the study's respondents, their perceived level of parental involvement has a direct influence on their reported level of educational adjustment. Thus, the more they perceived their parents' involvement in their academic life, the higher their reported level of educational adjustment (Beta=.50). Parental involvement was also found to have an indirect influence on their educational adjustment, being mediated by their reported level of self-efficacy. Thus, the more the respondents perceived their parents' involvement in their academic life, the higher their reported level of self-efficacy 
(Beta=.36); subsequently, the higher their reported level of self-efficacy, the higher their reported level of educational adjustment (Beta=.21). Self-efficacy was also found to be positively related to English language anxiety $(\mathrm{Beta}=.25)$ and negatively related to math anxiety (Beta=-.18). Thus, the higher the respondents' reported level of self-efficacy, the higher their reported level of English language anxiety and the lower their reported level of math anxiety. Neither English language anxiety nor math anxiety was found to be significantly related to the respondents' reported level of educational adjustment.

Discussion: The finding from the present study indicates that the parental involvement has a direct relationship with self-efficacy such that, the more the respondents perceived their parents' involvement in their academic life, the higher their reported level of self-efficacy. The present study substantiates earlier studies which demonstrated an association between parental involvement and self-efficacy. For example, it had been reported that parental support helps foster positive feelings and attitudes toward education and increases self-efficacy in children (Dearing, Kreider, Simpkins, \& Weiss, 2006). Similarly, parents' self-efficacy in their own parenting capabilities influences the development of their children (Pajares, 1996). The author posited that parents with a strong sense of confidence supervise, provide, protect, advice, and encourage their children. Moreover, they give time for their children, dispense needed discipline with emotional closeness, and keep open communication with them so that disagreements do not rise into open conflicts. It had been shown that parental involvement in a positive way can enhance better interactions with the environment and enhances self-efficacy and competency. The finding of the present study makes it clear that adolescent students are largely influenced by home environments that are characterized by warmth, fair and consistent standards for behavior, open communication, encouragement for self-reliance and autonomy, and effective monitoring of peer relations and social activities (Steinberg, 2001). It had been suggested that parental support can be extremely helpful to students going through the difficult transitions high school presents by helping students feel comfortable taking on challenges and risking failure (Daniel, Evans, \& Scott, 2001). The study used Grolnick's (2003) definition of parental involvement which includes spending time with and emotionally supporting children and his definition of parental autonomy support which is recognizing children's individual strengths and allowing them to make their own choices.

The results of the current study showed that perceived level of parental involvement has a direct influence on the participants' reported level of educational adjustment. Thus, the more they perceived their parents' involvement in their academic life, the higher their reported level of educational adjustment. This finding confirms the hypothesis of the present study. It was hypothesized that students' perceived level of parental involvement has a direct influence on their reported level of educational adjustment such that, the more they perceived their parents' involvement in their academic life, the higher their reported level of educational adjustment. Parental involvement has been identified as crucial in the development of schools and to attain student achievement (Conway and Houtenville, 2008). Researches also has supported that parental involvement has a positive impact on children even before they enter the school, and the impact continues throughout their educational journey, and their educational outcomes ( Sisson, 2008; Seginer, 2006). Gianzero (2001) stated that increased parental involvement enables students to achieve higher grades, improves student attendance, and improves students' conduct, attitude, and motivation. Based on the findings of the present study as well as those of related studies, it can be argued that students perform better when parents are involved in their education. Furthermore, the amount of parental involvement effort is consistently associated with students achieving at high levels. These implications are supported by the outcomes of many studies which demonstrated that parental involvement has direct positive effects on children's literacy (e.g., Dearing et al., 2006; Englund, Luckner, Whaley, \& Egeland, 2004). Greenwood and Hickman (1991) demonstrated that parent involvement at the secondary level has many positive benefits for students, the most important being enhanced student achievement. Other studies found that academic achievement, particularly of low-income students, is statistically correlated with effective parent involvement (Dwyer \& Hecht, 1992). These studies illustrate the need to include and involve parents in a variety of roles and areas, both at home and school. They also show the importance and the advantages of including parents as partners in the education of their children. Parental involvement had been documented as positively impacting students' math proficiency and achievement (Sheldon \& Epstein, 2005; Sirvani, 2007); gains in reading performance (Powell-Smith, Stoner, Shinn, \& Good, 2000); as well as performance on standardized tests and academic assessments (Domina, 2005). 
The present study revealed that self-efficacy is positively related to English language anxiety. Thus, the higher the respondents' reported level of self-efficacy, the higher their reported level of English language anxiety. This is a unique finding that has not been reported in past studies on self-efficacy. This current finding is contrary to past findings regarding the association between self-efficacy and English language anxiety. Bandura's (1991) in his theory of self-efficacy states that when a situation is perceived as threatening, the resultant anxiety is dependent on an individual's perception of his/her ability to deal positively with that threat. Bandura additionally argued that self-efficacy can act as a mitigating factor in anxiety-producing circumstances. By this, Bandura asserted that even if a student feels anxious about language learning, he/she can cope with this anxiety with his/her self-efficacy. In the present study, even if the respondents reported having high level of self-efficacy, this condition cannot act as a mitigating factor in anxiety-producing circumstances in the respondents. The students' strong negative attitude towards English language can be a probable reason for the outcome. It may be that in this case, the participants' level of self-efficacy, however, was not enough to reduce their English language anxiety. It had been suggested that negative attitudes can produce negative results in language learning, thus creating English anxiety (Vinson, 2001). Another possible explanation for the positive correlation between self-efficacy and English language anxiety is that the students involved may not be aware of their level of self-efficacy and its role in reducing language anxiety. It had been stipulated that learners' beliefs can predict performance better than their real ability (Bandura, 1997). For instance, students who successfully complete a very difficult project may not report high self-efficacy if they fail to recognize the skills they have developed and mastered during the successful process, or if the amount of effort necessary to complete the project overshadows the skills they developed and used in the process. Besides this, the students may not get enough encouragement from teachers or from peers to value their level of self-efficacy because they may become aware about their high level of self-efficacy concerning a specific task only when they receive encouragement from mentors, advisors, or superiors who are valued for their expertise in the particular domain assessed (Bandura, 1997).

The current outcome demonstrated that self-efficacy is negatively related to math anxiety. Thus, the higher the respondents' reported level of self-efficacy, the lower their reported level of mathematics anxiety. This finding echoes that of earlier studies which found that self-efficacy and math anxiety are negatively correlated; that is, high self-efficacy relates to low math anxiety and high math anxiety level indicates low self-efficacy, according to Pajares and Kranzler (1995). In the same vein, Pajares and Graham (1999) reported that self-efficacy is associated negatively with math anxiety. Using a joint path analysis to compare math self-efficacy and math anxiety in high school students, only math self-efficacy was found to be predictive of math performance. A possible explanation for this negative correlation between math anxiety and self-efficacy is based on Bandura's theory of self-efficacy. A number of studies (e.g., Bandura, 1986; Pajares, 1996) have all similarly demonstrated that self-efficacy beliefs predict students' mathematics performances and whether these performances are assessed as criterionreferenced test scores or achievement indices. Typically, self-efficacy predicts math performance to a greater degree than does previous math experience (Hackett, 1985) or self-efficacy for self-regulatory practices (Zimmerman, Bandura, Martinez-Pons, 1992).

As hypothesized in the study, there is a positive direct relationship between self-efficacy and educational adjustment, such that the higher the respondents' reported level of self-efficacy, the higher their reported level of educational adjustment. The present outcome is in line with past findings. More specifically, academic self-efficacy had been reported to promote academic achievement directly and also indirectly by increasing academic aspirations and pro-social behavior (Bandura, Barbaranelli, Caprara, \& Pastorelli, 1996). The results of the present study also revealed that parental involvement has an indirect influence on the respondents' level of educational adjustment, being mediated by their level of self-efficacy. Thus, the more the respondents perceived their parents' involvement in their academic life, the higher their reported level of self-efficacy; and subsequently, the higher their reported level of self-efficacy, the higher their reported level of educational adjustment. Past research investigated the influence of parental involvement on self-efficacy; it was shown that greater parental involvement in children's learning positively affects the child's school performance, including higher academic achievement (McNeal, 1999). Confirming the social environmental influences addressed in Bandura's (1997) social cognitive theory, empirical research gave evidence to the effect that children perceived a greater sense of competence when their parents were more involved in their education (Grolnick \& Slowiaczek, 1994), were more involved in school functions and had higher value for their children's education (Marchant, Paulson, \& Rothlisberg, 2001). The results of the present study also showed that the increased level of self-efficacy 
leads to better educational adjustment. A study conducted by Lent et al. (2008) found that self-efficacy and environmental support were predictive of goal progress and academic adjustment. Students reported gains in their academic functioning when they possess stronger self-efficacy and environmental support. It was identified by researchers that students' sense of efficacy affects their academic performance in various ways. For instance, Students with a strong sense of academic self-efficacy will be willingly to take up tasks that are challenging (Bandura \& Schunk, 1981), put in more effort (Salomon, 1984), and display lower anxiety levels (Meece, Wigfield, \& Eccles, 1990).

Limitations of the Study: There are several limitations in the present study that should be noted. First, the external validity of the study's findings is limited by the size of the sample which was obtained via convenience sampling. The sample consisted only of 300 students, out of a population of 2291 students studying in seven private schools under the Kottayam Diocese. Thus, the current findings cannot be generalized to larger populations of adolescents or High school students. Second, the psychosocial variables investigated in this study, although widely used in Western nations, are not well-researched within the Asian context. As such, the Western-based scales employed to collect relevant data may not have adequately measured what they purport to measure. Nonetheless, the cultural and other salient specificities of Asian contexts have not been included in the scale. Third, the theoretical perspectives and related studies reviewed to underpin the study's research questions and hypotheses were sourced primarily from Western-based literature. It could be argued that such Western-based literature may not be directly relevant or applicable to the Asian context; thus, the validity of the present study's findings may be questioned or deemed open for further verification. Nevertheless, in spite of these limitations, the current study is quite unique in itself as it offers new perspectives that serve to add to the literature. Moreover, an exploratory study of this nature may offer new avenues for further research.

\section{Conclusion}

This study carries a number of important implications for parents and teachers with regard to the educational services given to schoolchildren. Parents play a significant role in the education of their children. Parents have the ability to shape, nurture, and develop their children as active, positive, hardworking, perseverant, and emotionally stable students by having positive involvement in their studies and in their educational activities, in general. On the other hand, parents can also potentially destroy motivation and learning capabilities through negligence and indifference towards their children's achievements. Parental involvement helps foster positive feelings and attitudes toward education and increases self-efficacy in children. Parental involvement in school education has been identified as important. This has been supported by empirical researches that identied positive correlations between parental involvement in children's schooling and improved student attitude, achievement, and attendance (Gianzero, 2001). Hence, schools must intiative in designing programs or activities that enhances parental involvement.

Recommendations: The present school administrators should act decisively to get parental involvement in the educational process. To develop a healthy personality the school and the home should together shape the students. Self-efficacy is a significant factor in the learning process, so teachers need to take extra care and initiative to help students strengthen their self-efficacy. Students should be given opportunities to observe their peer group or fellow students who do tasks successfully; these opportunities encourage them to foster positive beliefs about themselves. According to the results of the current study, students who reportedly demonstrate high level of self-efficacy have high level of English language anxiety. It is recommended that teachers help students who are not aware about their level of self-efficacy and its usefulness in learning. This can be done by giving them positive strokes, encouraging them, praising their good works, and rewarding even their little positive efforts through positive reinforcement. Relative to students who are experiencing high level of English language anxiety; it is important to deal with anxiety-provoking situations carefully. Teachers should give more comprehensible input to their students. In order to provide more comprehensible input, teachers can slow down their speaking speed in class and make sure not to embarrass students by making them speak in class without preparation.

To parents: Parents need to recognize the continued importance of their relationship with their children. The educational adjustment of children depends in good measure on the quality of their relationship with their parents. Parents need to anticipate that their children require increased support from entry into 
high school onwards. Students need to feel that their parents are engaged in their school activities and are supportive of them. It is the duty of parents to provide necessities such as tuition fees, opportunities for group study with peers, and make available study guides, etc. All these will, to some extent, reduce the learning anxieties of their children. Furthermore, parents should always keep in mind that their high academic expectations can cause anxiety in their children. They must be aware of and accept the learning capability of their children.

To future researchers: The results of the present study highlight the need for more research on English language anxiety as well as math anxiety which would provide greater in-depth understanding of the factors associated with academic anxiety: fear of negative evaluation, test anxiety, and communication apprehension. Future studies on English language anxiety and/or math anxiety should be longitudinal in nature, in order to further explore changes in anxiety levels as students move from sheltered classes to more normal environments. The current results also indicated that involvement of parents in the educational activities of their children do not necessarily reduce their children's anxiety in English and/or math. In order to explore this phenomenon further, future researchers should consider parents' education level and socio-economic status as possible factors that may influence their children's learning. This study can be replicated with a more culturally diverse population and more culture-appropriate research instrumentation and methodology. Although the students in this study benefited from feedback complimenting their skills, students from other cultural backgrounds may not. In addition, replication of this study over a longer time frame could help to determine whether increases in self-efficacy could lead to eventual increases in academic achievement.

\section{References}

Bandura, A. (1991). Self-efficacy conception of anxiety. In R. Schwarzer \& R. A. Wicklund (Eds.), Anxiety and self-focused attention (pp. 89-110). London: Harwood Academic Publishers.

Bandura, A. (1977). Self-efficacy: Toward a unifying theory of behavioral change. Psychological Review, 84, 191-215.

Bandura, A., (1986). Social foundations of thought and action: A social cognitive theory. Englewood Cliffs, NJ: Prentice-Hall.

Bandura, A., Barbaranelli, C., Caprara, G. V. \& Pastorelli, C. (1996). Multifaceted impact of self-efficacy beliefs on academic functioning. Child Development, 67(3), 1206-1222.

Bandura, A. \& Schunk, D. H. (1981). Cultivating competence, self-efficacy, and intrinsic interest through proximal self-motivation. Journal of Personality and Social Psychology, 41, 586- 598.

Barbara, S. P. \& Parker, C. S. (1982). The development and validation of a revised version of the Mathematics Anxiety Rating Scale. Educational and Psychological Measurement, 42, 551-557.

Burns, M. (1998). Math: Facing an American phobia. Sausalito, CA: Math Solutions.

Cohen, M., Ben-Zur, H. \& Rosenfeld, M. J. (2008). Sense of coherence, coping strategies, and test anxiety as predictors of test performance among college students. International Journal of Stress Management, 15, 289-303.

Conway, K. S. \& Houtenville, A. (2008). Parental involvement strongly impacts student achievement. Journal of Human Resource, 43(2), 413-46.

Cotterall, S. (1999). Key variables in language learning: What do learners believe about them? System, 27, 493-513.

Dalziel, J. \& Peat, M. (1998). Fostering collaborative learning during student transition to tertiary education: An evaluation of academic and social benefits. In C. Rust (Ed.), Improving student learning: Improving students as learners (pp. 272-283). Oxford, UK: The Oxford Centre for Staff and Learning Development.

Daniel, B. B., Evans, S. C. \& Scott, B. R. (2001). Understanding family involvement in the college experience today. New Directions for student Services, 94, 3- 13.

Dearing, E., Kreider, H., Simpkins, S. \& Weiss, H. B. (2006). Family involvement in school and low-income children's literacy: Longitudinal associations between and within families. Journal of Educational Psychology, 98(4), 653-664.

Dirkx, J. (2001). The power of feelings: Emotion, imagination, and the construction of meaning in adult learning. New Directions for Adult and Continuing Education, 89, 63-72.

Domina, T. (2005). Leveling the home advantage: Assessing the effectiveness of parental involvement in elementary school. Sociology of Education, 78, 233-249. 
Dowdy, E., DiStefano, C., Dever, B. V. \& Chin, J. K. (2011). Screening for emotional and behavioral risk among students with limited English proficiency. School Psychology Quarterly, 26, 14-26.

Dwyer, D. J. \& Hecht, J. B. (1992). Causes underlying minimal parent involvement in the education of their children. Paper presented at the Annual Meeting of the Mid-Western Educational Research Association, Chicago, IL, USA. (ERIC Document Reproduction Service No. ED 353 059).

Englund, M. M., Luckner, A. E., Whaley, G. J. L. \& Egeland, B. (2004). Children's achievement in early elementary school: Longitudinal effects of parental involvement, expectations, and quality of assistance. Journal of Educational Psychology, 96(4), 723-730.

Gardner, R. C. \& Lambert, W. E. (1959). Motivational variables in second-language acquisition. Canadian Journal of Psychology/ Revue Canadienne de Psychologie, 13, 266-272.

Garris, R., Ahlers, R. \& Driskell, J. E. (2002). Games, motivation, and learning: A research and practice model. Simulation and Gaming, 33, 441-467.

Gianzero, G. (2001). Promoting parental involvement, improving student outcomes. A working paper $\begin{array}{lllll}\text { prepared for } & \text { San Diego }\end{array}$ http://www.sandiegodialogue.org/pdfs/parentalinvolvement.doc.pdf

Greenwood, G. E. \& Hickman, C. W. (1991). Research and practice in parent involvement: Implications for teacher education. Elementary School Journal, 91(3), 279-288.

Grolnick, W. S. (2003). The psychology of parental control: How well-meant parenting backfires. Mahwah, NJ: Erlbaum.

Hacket, G. (1985). The role of mathematics self-efficacy in the choice of math-related Majors of college women and men: A path analysis. Journal of Counseling psychology, 32, 47- 56.

Hoover-Dempsey, V. K., Wilkins, A., Sandler, H. \& O' Connor, K. (2004). Parental role construction for involvement: Theoretical measurement and pragmatic issues in instrument development. Paper presented at the annual meeting of the American Educational Research Association, San Diego, CA, USA.

Horwitz, E. K. (1986). Preliminary evidence for the reliability and validity of a foreign language anxiety scale. TESOL Quarterly, 20, 559-562.

Horwitz, M. B., Horwitz, E. K. \& Cope, J. A. (1986). Foreign language classroom anxiety. The Modern Language Journal, 70(2), 125-132.

Khawaja, N. G. \& Dempsey, J. (2007). Psychological distress in international university students: An Australian study. Australian Journal of Guidance and Counseling, 17, 13-27.

Lent, R. W., Sheu, H. B., Singley, D., Schmid, J. A., Schmidt, L. C. \& Gloster, C. S. (2008). Longitudinal relations of self-efficacy to outcome expectations, interests, and major choice goals in engineering students. Journal of Vocational Behavior, 73(2), 328-335.

Marchant, G. J., Paulson, S. E. \& Rothlisberg, B. A. (2001). Relations of middle school students' perceptions of family and school contexts with academic achievement. Psychology in the Schools, 38(6), 505519.

Mclnnis, C. (2001). Researching the first year experience: Where to from here? Higher Education Research \& Development, 20, 105-114.

Mclnnis, C. \& James, R. (1995). First year on campus: Diversity in the initial experience of Australian undergraduates. Canberra, Australia: AGPS.

Meece, J. L., Wigfield, A. \& Eccles, J. S. (1990). Predictors of math anxiety and its influence on young adolescents' course enrollment intentions and performance in mathematics. Journal of Educational Psychology, 82, 60- 70.

McNeal, R. B., Jr. (1999). Parental involvement as social capital: Differential effectiveness on science achievement, truancy, and dropping out. Social Forces, 78(1), 117-144.

Miedel, W. T. \& Reynolds, A. J. (2000). Parent Involvement in early intervention for disadvantaged children: Does it matter? Journal of School Psychology, 37, 379- 402.

Misra, R., Crist, M. \& Burant, C. J. (2003). Relationships among life stress, social support, academic stressors, and reactions to stressors of international students in the United States. International Journal of Stress Management, 10, 137-157.

Multon, K. D., Brown, S. D. \& Lent, R. W. (1991). Relation of self-efficacy beliefs to academic outcomes: A meta-analytic investigation. Journal of Counseling Psychology, 38(1), 30-38.

Olivas, M. \& Li, C. S. (2006). Understanding stressors of international students in higher education: What college counselors and personal need to know. Journal of Instructional Psychology, 33, 217-222.

Pajares, F. (1996). Self-efficacy beliefs in academic settings. Review of Educational Research, 66(4), 543578. 
Pajares, F. \& Graham, L. (1999). Self-efficacy, motivation constructs, and mathematics Performance of entering middle school students. Contemporary Educational Psychology, 24, 124-139.

Pajares, F. \& Kranzler, J. (1995). Self-efficacy beliefs and general mental ability in mathematical problemsolving. Contemporary Educational Psychology, 20, 426- 443.

Powell-Smith, K. A., Stoner, G., Shinn, M. R. \& Good, R. H. (2000). Parent tutoring in reading using literature and curriculum materials: Impact on student achievement. School Psychology Review, 29(1), 5-27.

Ruffins, P. (2007). A real fear. Diverse Issues in Higher Education, 24(2), 17-19.

Salomon, G. (1984). Television is "easy" and print is "tough": The differential investment of mental effort in learning as a function of preconceptions and attitudes. Journal of Educational Psychology, 76, 647- 658.

Schwarzer, R. \& Jerusalem, M. (1995). Generalized Self-Efficacy Scale. In J. Weinman, S. Wright, \& M. Johnston, Measures in health psychology: A user's portfolio. Causal and control beliefs (pp. 3537).

Sheldon, S. B. \& Epstein, J. L. (2005). Involvement counts: Family and community partnerships and mathematics achievement. The Journal of Educational Research, 98(4), 196-206.

Sirvani, H. (2007). The effects of teacher communication with parents on students' mathematics achievement. American Secondary Education, 36, 31-46.

Sisson, G. (2008). Parent involvement in education continues in high school. Retrieved from http:// www. eduguide. Org/ Parent- Involvement-in-Education -at- High School.

Steinberg, L. (2001). We know some things: Parent- adolescent relationships in Retrospect and prospect. Journal of Research on Adolescence, 11, 1-19.

Tremblay, P. F. \& Gardner, R. C. (1995). Expanding the motivation construct in language learning. The Modern Language Journal, 79, 505-518.

Vernon-Livington, N. (2009). Influence of parenting and coping styles on adjustment to first year university (Unpublished bachelor dissertation). University of the Sunshine Coast, Australia.

Vinson, B. (2001). A comparison of pre-service teachers' mathematics anxiety before and after a methods class emphasizing manipulative. Early Childhood Education Journal, 29, 2, 89-94.

Walsh, K. (2008). The relationship among mathematics anxiety, beliefs about mathematics, mathematics self-efficacy, and mathematics performance in associate degree nursing students. Nursing Education Perspectives, 29(4), 226- 229.

Zajacova, A., Lynch, S. M. \& Espenshade, T. J. (2005). Self- efficacy: Stress and academic success in college. Research in Higher Education, 46, 677-706.

Zimmerman, B. J. (2000). Self-efficacy: An essential motive to learn. Contemporary Educational Psychology, 25, 82-91.

Zimmerman, B. J., Bandura, A. \& Martinez- Pons, M. (1992). Self-motivation for academic attainment: The role of self-efficacy beliefs and personal goal setting. American Educational Research Journal, 29, 663-676. 